\title{
"A TODOS NOS COUBE VIVER A CRUELDADE DESTE TEMPO". DA ESFERA ÍNTIMA À HISTÓRICA, A VOZ DO POETA PARTILHADA
}

\author{
"LIVING THIS TIME'S CRUELTY IS EVERYONE'S DUTY". \\ FROM INTIMACY TO HISTORY, THE POET'S VOICE SHARED
}

Mayra Moreyra Carvalho

Universidade de São Paulo

São Paulo - Brasil

\begin{abstract}
In December 1958, Rafael Alberti received an anonymous letter sent from a prison in Spain. In June 1959 his answer "Carta a los presos de España" ("Letter to the Prisoners in Spain") was published. A reading of these two letters, exchanged when the poet was exiled in Argentina, reveal intentions that surpass the idea of intimacy expected of this genre. This paper aims to read these letters from a wider perspective, one that takes into account both the limits to the action of the poet and poetry and also, the historical context in the 50's and the 60's, a period in which we cannot ignore the role played by intellectuals confined in Spanish prisons, the movement for amnesty for political prisoners in Spain and Portugal and the ideological tensions resulting from the Cold War.
\end{abstract}

Keywords: Letters, intimate writing, exile, poetry, history.

\section{Resumen}

En diciembre de 1958, Rafael Alberti recibe una carta anónima escrita desde una cárcel en España. En junio de 1959 se publica su respuesta, "Carta a los presos de España”. La lectura de esas correspondencias, intercambiadas cuando el poeta se encontraba en el exilio en Argentina, desvela intenciones que rebosan el ámbito íntimo, expectativa que el género textual genera. Nos proponemos leer esas cartas desde una perspectiva más amplia, que significa reflexionar sobre los límites de la acción del poeta y de la poesía; y considerar el contexto histórico de los años 50 y 60 , cuando no se puede

\section{Resumo}

Em dezembro de 1958, Rafael Alberti recebe uma carta anônima escrita em uma prisão na Espanha. Em junho de 1959, vem à luz sua resposta, "Carta a los presos de España”. A leitura dessas correspondências, trocadas quando o poeta estava exilado na Argentina, desvela intençóes que ultrapassam o âmbito íntimo, expectativa primeira criada pelo gênero textual. Propomos ler essas cartas numa perspectiva mais ampla, o que implica refletir sobre os limites da ação do poeta e da poesia; e considerar a conjuntura histórica na passagem dos anos 50 para os 60 , quando não se pode 
ignorar el rol de los intelectuales detenidos en las cárceles españolas, el movimiento por la amnistía de los presos políticos en Espańa y Portugal y las tensiones ideológicas de la Guerra Fría.

Palabras claves: Cartas, escritura íntima, exilio, poesía, historia. ignorar o papel dos intelectuais detidos em prisões espanholas, o movimento pela anistia de presos políticos na Espanha e em Portugal e o acirramento das tensóes ideológicas decorrentes da Guerra Fria.

Palavras-chave: Cartas, escrita íntima, poesia, exílio, história.

\section{Introdução}

Em dezembro de 1958, o poeta Rafael Alberti (1902-1999) recebeu uma carta anônima remetida de uma prisão na Espanha. É importante saber que, naquele ano, Alberti se encontrava exilado na Argentina, onde havia chegado com sua esposa, a também escritora María Teresa León, em 1940 depois da derrota republicana ao final da Guerra Civil Espanhola (1936-1939). Ambos haviam permanecido em Madri durante praticamente todo o conflito, e tiveram participação ativa à frente das açôes da Aliança de Intelectuais Antifascistas, que incluíram a montagem de peças de teatro, a publicação do periódico El mono azul e a compilação do Romancero de la Guerra Civil Española. Na Argentina, o casal viveria primeiro na província de Córdoba e logo em Buenos Aires, até 1963, quando partiria rumo à Itália. O retorno à Espanha só ocorreria em 1977 após a morte do ditador Francisco Franco.

Esse longo itinerário do casal Alberti-León se insere num contexto maior que compreende o enorme contingente de pessoas - em torno de 450.000 no imediato pós-Guerra Civil Espanhola (CAUDET, 2002; SALAÜN, 2002) - que conformaram o Exílio Republicano de 1939, um dos mais numerosos e duradouros do século XX. O fenômeno teve a particularidade de atingir duramente a intelectualidade espanhola, pois uma quantidade expressiva de artistas, cientistas, profissionais liberais, políticos, escritores e poetas foi desterrada. Muitos desses chegaram a países da América Latina, em especial o México, principal apoiador da causa republicana; outros permaneceram refugiados na Europa, e houve os que foram enviados a campos de concentração na França e no norte da África, como aconteceu com o escritor Max Aub (1903-1972), ou na Alemanha, para onde foi mandado Jorge Semprún (19232011). Vicente Llorens, ao mapear os nomes e os destinos dos intelectuais republicanos exilados, denomina o fenômeno como um "verdadeiro exílio poético" ao constatar que, dos dezessete poetas que figuravam na antologia de poesia espanhola compilada por Gerardo Diego em 1932, dez haviam partido para o exílio e dois haviam morrido em decorrência da Guerra Civil, Federico García Lorca e Miguel Hernández (2006, p. 259). 
Rafael Alberti responde a carta anônima em 01 de abril de 1959, com o título de "Carta a los presos de España". Alguns meses mais tarde, em junho, essa resposta é publicada no número 9 do boletim de informação da Unión de Intelectuales Españoles en México. ${ }^{1}$ Finalmente, em 1976, a carta anônima do prisioneiro, que havia sido remetida ao poeta em 1958, ganha publicação na revista Litoral, ${ }^{2}$ no número intitulado "Poesía en la cárcel. Historia del enfrentamiento de los poetas contra los abusos del poder".

Sendo cartas, esses dois textos criam uma expectativa no leitor. Sem dúvida, espera-se que a correspondência atenda à função mais básica da comunicação (CABALLÉ, 2015), e que se restrinja ao âmbito da intimidade, ou seja, que o que vá escrito na epístola diga respeito aos dois sujeitos envolvidos - remetente e destinatário -, e a mais ninguém. Esta seria, nas palavras de Pedro Salinas, a "carta pura", aquela que tem "vontade de pudor" (2007, p. 861). No entanto, o próprio Salinas adverte que a carta é um terreno resvaladiço (2007, p. 865), no qual incide a intenção do escrevente, e estão implicadas relaçóes que ultrapassam os limites das duas pontas primárias, de modo que é preciso considerar um "mais aquém", anterior ao próprio autor que, afinal, é o primeiro leitor da carta e o primeiro a ser atingido por seus efeitos; e um "mais além", que seria o alcance máximo da carta, quando ela atinge o grande público (2007, p. 868).

Diante da complexidade do gênero, uma mesma pergunta surge em vários estudos: "A quem pertence uma carta?", se interroga Philippe Lejeune (1998), ou "A quem se dirige uma carta?", questiona o mesmo Salinas (2007, p. 868).

Nossa proposta neste artigo é justamente lançar essas perguntas sobre as correspondências trocadas entre o preso anônimo de uma cadeia espanhola e o poeta Rafael Alberti, pois a leitura atenta desses dois textos desvela intençóes

1 A Unión de Intelectuales Españoles en México foi fundada em 21 de julho de 1947, sob a direção de León Felipe, Max Aub, José Renau e Moisés Barrio Duque, entre outros. O boletim de informaçấo da entidade tinha como objetivo criar laços entre os intelectuais espanhóis antifranquistas que viviam no exterior e aqueles que residiam no país, como se lê no primeiro número, de 15 de agosto de 1956. Para tanto, divulgavam as produções e as ações culturais de uns e de outros. O boletim foi publicado até 1961.

2 A revista Litoral foi uma publicação de especial relevo no contexto da chamada "Generación del 1927". Como afirma Julio Neira, foi a revista mais significativa e emblemática daquele período (2007, p. 7). Nasceu em novembro de 1926 em Málaga sob a direção dos poetas Emilio Prados e Manuel Altolaguirre, dedicando-se à poesia, às artes plásticas e à música. A primeira época teve oito números (novembro de 1926 a outubro de 1927), entre os quais se destacam os três publicados em homenagem a Góngora, uma das açōes pelas quais o grupo de artistas ficou conhecido. A segunda, a que se incorporou José María Hinojosa, compreendeu a publicação de duas ediçóes no ano de 1929. Já no exílio mexicano, em 1944, José Moreno Villa, Juan Rejano e Francisco Giner de los Ríos retomam as publicaçōes ao lado dos fundadores Prados e Altolaguirre. Três números são publicados naquele ano. José María Amado é quem refunda a revista em 1968 em Málaga. Atualmente, a revista ainda existe e conta com a participação de Lorenzo Saval, sobrinho neto de Emilio Prados. Descreve-se como uma "revista de poesía, arte y pensamiento". 
que ultrapassam o âmbito íntimo e nos convoca a investigar onde repousariam o "mais aquém" e o "mais além" dessa relação epistolar.

Lendo as cartas: tensões e intenções na esfera íntima

Começamos nossa reflexão com a leitura do parágrafo de abertura da carta anônima:

Querido, Rafael: Apesar da censura do Regime franquista, que fuzila, inutilmente, a palavra do Homem e suas ideias, lemos, emocionados, muitos de teus poemas. Nem mesmo na dor do êxodo podes considerar-te um poeta sem raízes. Ainda seguem ressoando pela Pátria invadida tuas lindas cançóes, aqueles velhos cantos que nossos coraçóes de soldado aprenderam de memória. Nem os muros das prisóes puderam impedir que tua palavra chegasse até nós. Teus poemas, arraigados na alma do povo, foram passando, de mão em mão, como uma bandeira clandestina. E no centro mesmo do terror, no silêncio dos presídios, rendemos-te frequentes homenagens, e repartimos tua voz como um pão vermelho entre os homens. (ANÔNIMO, 1976, p. 233) ${ }^{3}$

O primeiro aspecto que chama a atenção no texto é sua organização reiterativa, evidenciada pela profusão de vocábulos dos universos semânticos da "voz" e do "som". Por exemplo, neste excerto, e em outras passagens da carta, encontramos verbos como "ressoar", "renunciar" e "transmitir"; ou formulaçóes como "repartir a voz", "a voz que pode estremecer o mundo", "um grito que fere as janelas", "a voz sem fronteiras clama pela vida”, "pronunciar o nome da pátria com voz plena e legítima”, entre outras.

$\mathrm{Na}$ resposta de Alberti, por sua vez, o poeta assume o papel de "depositário da voz dos presos políticos espanhóis" e afirma que as ouve. Além disso, ele identifica o Valle de los Caídos, ${ }^{4}$ cuja construção havia terminado em 1958 - portanto, pouco antes da redação desta carta -, como uma tentativa de "fechar com o silêncio as cicatrizes da Espanha" (ALBERTI, 1997, p. 114).

O que este breve levantamento pode significar? Acreditamos que essas ocorrências sinalizam, principalmente no caso da carta anônima do preso, que os autores exploram a reiteração de referências a um mesmo universo semântico como elemento discursivo. $\mathrm{O}$ primeiro efeito que se alcança é o de impregnar os textos com um teor de denúncia e reivindicação, que consequentemente os recobre de uma eloquência que náo pode ser abafada

3 Tradução minha. Todas as demais traduçôes de citaçōes a partir do espanhol neste artigo (além da carta anônima; da resposta de Rafael Alberti, dos fragmentos de Francisco Ayala, Manuel Aznar Soler e Marcos Ana) são de minha autoria.

$4 \mathrm{O}$ Valle de los caídos é um memorial de guerra construído nos arredores de Madri durante os primeiros anos da ditadura franquista para enterrar principalmente combatentes e partidários do bando nacionalista. 
pelos limites da comunicação íntima. No caso da carta anônima, embora se dirija a Rafael Alberti e insista na repetição do vocativo, nem tudo o que está sendo dito é somente para que este poeta leia e saiba.

Por um lado, a missiva quer lhe dar notícias de que sua poesia escrita no exílio chega e é lida na Espanha, ainda que por vias clandestinas. O fato de ter dado ciência dessa repercussão certamente foi de extrema importância para Alberti, já que entre as maiores preocupaçóes dos poetas, escritores e intelectuais da chamada "Espanha Peregrina"5 estava a chegada de sua obra até os leitores que mais precisavam lê-la e conhecê-la. Acerca deste problema, é propício recordar o conhecido ensaio de Francisco Ayala (1906-2009), de 1948, em que o autor, também um exilado republicano, se interroga justamente sobre a natureza da obra e sobre o público leitor dos escritores espanhóis que haviam sido desterrados. Ayala repercute uma questão que pode ser rastreada em toda a produção ensaística, ficcional e lírica desse grupo:

Para quem nós escrevemos? Eu, espanhol na América, para quem escrevo? $[\ldots]$

Quero mostrar com isso como, não só os intelectuais exilados, como também os que permanecem em solo espanhol [...] perdemos todos a possibilidade de nos dirigirmos a essa comunidade ativa, tosca e amarga, sim, mas sensível, que era a nação espanhola [...].

Pois bem: consideremos de novo as condiçóes do escritor emigrado, para relacioná-las ao caso do criador literário, desconectado - desgarrado, pode-se dizer, pela violência e brutalidade do golpe que o separou - da comunidade onde se formou, e privado quase por completo do público espanhol, ao qual com dificuldades e mediações chegam seus escritos. $\mathrm{O}$ fundo de realidade concreta em função da qual ele escrevia lhe foi, pois, arrancado, com a dupla consequência de cortar-lhe, a um só tempo, os estímulos naturais para sua produçáo e o destinatário a quem em primeiro lugar tinha que se dirigir. (1984, p. 181, 184 e 196)

Por outro lado, a carta fala da censura imposta pelo franquismo, dos fuzilamentos, das prisóes, do terror e do silêncio, fatos sobre os quais Alberti certamente já tivera notícia àquela altura por outros meios. Nesse sentido, não é só ao poeta que a carta parece querer contar sobre aquela realidade, pois as denúncias que ela faz a cada passo extrapolam a esfera da intimidade

5 Aqui nomeamos o enorme contingente de intelectuais republicanos exilados com os termos com os quais José Bergamín (1895-1983) batizou a revista de difusão cultural fundada em 1940 no México a fim de manter unidos os exilados e zelar pela cultura espanhola que estava em risco pela dispersão de seus produtores. Bergamín inspirou-se na obra El peregrino en su patria de Lope de Vega para intitular a publicação. España Peregrina teve nove números publicados entre fevereiro e outubro de 1940, nos quais figuraram ensaios, artigos e resenhas sobre autores e obras hispânicas, e poemas de nomes como Luis Cernuda e Francisco Giner de los Ríos (CAUDET, 1977). 
prevista para uma correspondência. No fragmento abaixo, a veemência das revelaçóes é patente:

Parece que está fora de todo cálculo sobre a resistência humana o que suportamos sem enlouquecer, sem relaxar um músculo de nossa luz, sem renunciar, sem deixar cair um só pedaço de bandeira. Vimos embranquecer os cabelos de nossas noivas; morrer nossas mães, afogadas pelo pranto; crescer nossos filhos em uma dura ausência; e secar nossas leais mulheres, ano após ano, nos umbrais das prisóes. Tocamos, mil vezes, a mão da Morte ao terem sido arrancados dos nossos braços os melhores amigos, quando não o pai ou os nossos irmãos. (ANÔNIMO, 1976, p. 233-234)

Ao lado dessas denúncias, a voz que fala nesta carta - ou vozes, já que o remetente se identifica como um "nós" - advoga pela necessidade do diálogo sem temor e reivindica o direito à palavra. Para tanto, o texto cumpre um itinerário: ele contrapóe a tentativa sistemática do regime franquista de silenciar as vozes dos dissidentes de dentro e de fora do país com a perenidade da voz que fala através da arte literária. É isso que se conta ao poeta na carta: que a sua voz atravessou as barreiras da distância e da repressão e foi repartida entre os presos. Mas não só, pois essa voz tem uma força capaz de alentar a escritura desta mesma carta, ou seja, os presos-remetentes - que se descrevem como "derrotados, mas jamais vencidos; torturados, mas ilesos no pensamento e na esperança" (ANÔNIMO, 1976, p. 233) - foram animados pela palavra poética e revelam acreditar nela como um instrumento que pode fazer com que o inaudito seja ouvido. Por esta razão, eles não só reivindicam sua própria voz, mas elegem Rafael Alberti como portador de sua causa:

É preciso um poeta que cante nossa morte infinita. Quem como tu, Rafael? Que voz pode estremecer o mundo como a tua? [...] Nossa palavra sangra crucificada nos ferrolhos. Náo fere tuas janelas o resplendor de um grito? Necessitamos tua palavra. Que tua voz sem fronteiras clame por nossa vida. (ANÔNIMO, 1976, p. 233)

Com efeito, este é o compromisso que Alberti selará em sua resposta em abril de 1959:

Um a um, eu, Rafael Alberti, sinto-me designado por vocês para ser depositário de suas vozes, tão bela através dos sofrimentos vividos, tão varonil, tão forte. Gostaria de dizer a vocês que a empreitada de sua liberdade nos une à mais alta e imperiosa da liberação da Espanha.

$[\ldots]$ 
Escreverei em seus nomes e no meu uma carta aos poetas da Espanha, reatarei o diálogo interrompido e juntos traçaremos a nova grande paixáo de paz e convivência humana buscando abrir as portas das prisóes. (ALBERTI, 1997, p. $113 ; 115)$

Alberti, de fato, escreveu a carta aos poetas espanhóis conforme prometera em sua resposta. Ela aparece em forma de poema com o nome de "Carta abierta a los poetas, pintores, escritores... de la España Peregrina", na obra Signos del día, de 1961. O título guarda uma referência à própria obra de Rafael Alberti: "Carta abierta”, de Cal y canto (1929), é um poema frequentemente considerado pela crítica como revelador de um momento de inflexão importante para o poeta. De fato, a composição condensa fulgurações da crise estética e pessoal que ocupará, sobretudo, um de seus livros mais complexos e densos, Sobre los ángeles, de 1929 (HANSEN, 2002).

É interessante a escolha pelo mesmo nome, pois na "Carta abierta" da década de 1920 pulsava um problema eminentemente íntimo entregue ao âmbito público, pondo em tensão os limites das duas esferas. Na "Carta abierta..." dos anos 50, semelhante tensão se nota, mas ocorre quase de forma inversa: o fato histórico chama o sujeito à participação. Na condição de exílio, o oficio poético não discerne ser social e dor íntima, razão pela qual os versos se valem da concepçáo de que o poeta e sua palavra têm um poder interventor com sua "pluma delatora”, e que deixar de usá-la equivale a entregar-se à morte (ALBERTI, 2006, p. 234). Nesse sentido, Alberti lança mão da figura do "poeta atuante", cujas escolhas estéticas não se separam de um posicionamento político e de uma "intervenção no espaço social" (MIRANDA, 2016, p. 247-249), ratificando uma atitude assumida em sua poesia desde o início dos anos 30, quando se identifica como "o poeta na rua" ${ }^{6}$

Assim, a carta de resposta aos presos e a carta-poema ratificam um traço que percorre todos os escritos de Rafael Alberti: trata-se da crença na palavra e na criação, razão pela qual não é equivocado dizer que este é um poeta de fé, ainda que tensóes estejam presentes ao longo de sua obra. Por isso, na Carta abierta... se lê que é a fé de seu fatigado coração que vacila que lhe permite dirigir-se aos seus companheiros, "pobres e errantes ossos desterrados e atirados longe da Espanha", mesmo depois dos tantos anos de noite escura, ${ }^{7}$ de tanta morte, de tanto esquecimento; mesmo depois de

6 "El poeta en la calle" é o título sob o qual, a partir de 1978 e por desejo do poeta, são agrupados poemas escritos entre 1931 e 1936 publicados em diferentes periódicos. Trata-se de uma expressão com a qual Alberti se autodesignara e pela qual também ficara conhecido desde os anos 30 .

7 "Cuando después de tantos años de noche oscura" é o primeiro verso da segunda estrofe de "Carta abierta...". O sintagma "noite escura" evoca o célebre poema de San Juan de la Cruz (1543-1591), incontestável referência para a literatura dos exilados espanhóis. A noite escura é o cenário da busca da Amada, a alma humana, por Deus, o Amado, ao qual ela finalmente se funde no encontro. As ideias de plenitude 
tantos depois sem aparente vislumbre de uma luz (ALBERTI, 2006, p. 234).

Como podemos observar, a trama discursiva das duas correspondências - a anônima dos presos e a resposta de Alberti -, ao explorar a repetição dos elementos "voz" e "som", denota que elas não têm "a vontade de pudor da carta pura", como dizia Salinas (2007). Antes, têm a vontade do despudor, e, mais do que isso, a vontade do desvelo. Essas cartas querem fazer ouvir e fazer saber, causar desconcerto. Portanto, o destinatário Rafael Alberti na primeira carta, e os destinatários-presos na segunda são, no dizer de Salinas, "pontes para passar a outra margem" (2007, p. 867).

Vistas sob essa perspectiva, as duas correspondências põem em relevo a faceta da "carta como ato", um dos três aspectos que Marco Antonio de Moraes, na esteira das consideraçóes de Lejeune (1998), identifica no texto epistolar. Esta faceta corresponde ao "caráter performativo" da carta, pois "a mensagem póe em marcha pensamentos, projetos" (MORAES, 2009, p. 116). Ora, as características que observamos nas duas cartas, ao ultrapassar o âmbito íntimo, exigem que nos perguntemos: Que projeto essas correspondências póem em marcha? E a que outra margem os autores envolvidos nesses textos queriam chegar?

Para além da intimidade: a esfera histórica

Consideradas dentro da complexa conjuntura histórica na passagem dos anos de 1950 para 1960 - lembrando que se escrevem em dezembro de 1958 e abril de 1959 -, podemos localizar as duas cartas dentro de uma rede de problemáticas que envolvem a situação dos detidos em prisôes espanholas, o movimento internacional pela anistia de presos políticos na Espanha e em Portugal, e o acirramento das tensóes ideológicas decorrentes da Guerra Fria.

Nesse contexto, surge como figura importante Fernando Macarro Castillo, que adotou o nome de Marcos Ana, pelo qual ficou conhecido como militante comunista, soldado durante a Guerra Civil Espanhola, preso político que mais tempo ficou encarcerado durante o franquismo - foram 22 anos, de maio de 1939 a novembro de 1961 - e poeta. Marcos Ana havia conhecido Rafael Alberti e María Teresa León no início da Guerra Civil, mas é em meados dos anos 50 , quando era prisioneiro na penitenciária de Burgos, no centro-norte da Espanha, - el Penal de Burgos - que se torna leitor e correspondente assíduo do casal (AZNAR SOLER, 2003).

A concentração de presos políticos em Burgos - mais de 400, segundo números de 1961 - fez com que se organizassem movimentos dentro da prisão, apelidada de Universidade de Burgos, porque ali os presos se desenvolveram

e totalidade implicadas em San Juan são postas em perspectiva e tensionadas quando a noite escura passa a figurar o vagar incerto a que obriga a condiçáo de desterrado. 
como leitores e chegaram até a encenar peças escritas por eles, por exemplo, a homenagem a Alberti e María Teresa, como refere o alentado estudo de Manuel Aznar Soler sobre os cárceres franquistas:

[...] as atividades políticas e culturais que os presos desenvolviam clandestinamente haviam convertido aquela prisão de Burgos na chamada "Universidade de Burgos", desde a qual Marcos Ana, por exemplo, havia podido iniciar o contato epistolar com Alberti e, sobretudo, com María Teresa León $[\ldots]$.

Todos eles iam realizar naquela "universidade" burgalesa seu doutorado poético [...] Entre Marcos Ana, María Teresa León y Rafael Alberti, entre a prisão de Burgos e o exílio de Buenos Aires, construiu-se uma bela ponte de versos e cartas, de fraterna solidariedade militante, que me parece de estrita justiça ressaltar. (2003, p. 453-454).

É na clandestinidade dessas ações que esses presos começam a articular, apoiados por suas famílias fora da prisão e por intelectuais exilados, a campanha internacional de anistia dos presos políticos na Espanha e em Portugal. Na América Latina, a campanha ganha força com a chegada à Argentina em 1959 do poeta Luis Alberto Quesada, que havia sido liberado exatamente da mesma prisão de Burgos; e do também poeta e crítico Jacinto Luis Guereña - ambos haviam combatido pela causa republicana durante a Guerra Civil Espanhola. Esses nomes se juntam a exilados das ditaduras ibéricas na Argentina, no Uruguai, no Chile e no Brasil e formam a Organização Americana Pró-Anistia para os presos políticos da Espanha e de Portugal.

Rafael Alberti e Maria Teresa León estão conectados, desde Buenos Aires, a todo esse movimento. O casal participa de atos pela liberdade na Espanha e de denúncia da ditadura franquista mesmo antes de 1959. Durante a década de 1940, por exemplo, haviam colaborado com publicaçóes como España Republicana, periódico do Centro Republicano Espanhol de Buenos Aires, que foi o veículo de caráter político mais importante dos exilados republicanos da Argentina (DÍAZ-REGAÑON LABAJO, 2006, p. 912); e Pensamiento Español, o qual buscava despertar a solidariedade, o apoio e a esperança dos desterrados e com relaçáo a eles, como se anuncia no primeiro número de 1941 (FUNES; SANZ, 2016, p. 48).

As reivindicaçôes que traziam à luz a condição dos presos políticos na Península Ibérica se inserem, por sua vez, na conjuntura tensa da Guerra Fria naqueles anos. Sumariamente, podemos apontar os seguintes fatos relevantes: em 1957, a URSS lança o Sputnik; em janeiro de 1959, triunfa a Revolução Cubana; entre 1959 e 1960, assiste-se a uma escalada dos conflitos da Guerra do Vietnă; em 1961, John Kennedy ascende à presidência dos EUA; e em fevereiro de 1961, deflagra-se em Angola um movimento contra a dominação 
portuguesa, mesmo ano em que se dá a construçáo do muro de Berlim pela URSS. Além desses acontecimentos, ocorre o sequestro do transatlântico Santa Maria em janeiro de 1961, mais diretamente relacionado coma pressão à ditadura salazarista; e em agosto de 1961, os Estados Unidos dáo início a seu plano de desenvolvimento para América Latina, que selaria a primazia norte-americana no continente e se desdobraria na colaboração às ditaduras latino-americanas das décadas de 60 e 70.

Este breve panorama do cenário mundial evidencia um momento em que as tensóes ideológicas estavam à flor da pele. Situando as cartas neste cenário, constatamos que, de fato, elas não só sinalizam a vontade de despudor de que falávamos, mas também respondem à urgência daquele tempo. Com efeito, vistas "de lá para câ", ou seja, quando estamos cientes desse contexto maior, a potência que impregna o discurso das cartas ganha ainda mais força.

Não por acaso, Manuel Aznar Soler (2003), ao reconstruir a trajetória de Marcos Ana, aponta como exemplo das correspondências entre ele e Rafael Alberti justamente a carta anônima enviada ao poeta em dezembro de 1958. Embora Manuel Aznar não afirme que a missiva é de autoria de Marcos Ana, ao localizá-la nessa conjuntura maior de luta pela anistia que descrevemos brevemente, permite-nos refletir acerca da autoria e do anonimato enquanto recursos discursivos, assim como sobre o papel social do poeta e da poesia.

A este respeito, convém fazer referência ao testemunho que Marcos Ana apresentou no congresso que celebrou o centenário de Alberti em 2002: “[...] com Rafael tinha e tenho uma dívida impagável de solidariedade, pois nas horas mais incertas de meu cativeiro estendeu meu nome e defendeu com sua palavra minha liberdade e minha vida" (2004, p. 13). Nesta declaração, ecoam evidentemente as formulaçóes da carta anônima de 1958, principalmente no que tange às reivindicaçóes dos presos e ao compromisso assumido por Alberti, os quais passam pelo direito à voz e pelo dever de fazer uso dela.

Desse modo, permanece para nós como interrogação final: por que a carta de 1958 não é assinada? Por que a opção pelo anonimato? Considerando todo o complexo contexto que apontamos, sem desprezar a perspicácia desses dois poetas - Alberti e Marcos Ana - e lembrando um aspecto marcante da carta como gênero - o fato de que, como afirma Marco Antonio de Moraes, "o correspondente epistolar, [...], é sempre um manipulador de sensaçóes e de realidades" (2007, p. 32) -, é possível dizer que anonimato é um recurso que potencializa tanto os problemas que a carta denuncia como as questóes que ela reivindica.

Por um lado, o anonimato expóe a obrigatoriedade do silêncio, a violência da censura e o perigo que representa carregar um nome que é perseguido por um regime ditatorial. Mas, ao mesmo tempo, ele permite falar em nome de um "nós", e evidencia que a questão do direito à palavra e 
à liberdade não diz respeito só a um indivíduo. Com efeito, como se lê numa passagem marcante da primeira carta: "A todos nos coube viver a crueldade deste tempo" (1976, p. 234).

\section{Considerações finais}

A leitura atenta da correspondência anônima enviada a Rafael Alberti por um preso político espanhol em 1958 e de sua resposta, datada do ano seguinte, levou-nos a observar a peculiar armação discursiva desses dois textos. Organizadas a partir da reivindicação por uma voz plena e legítima capaz de se erguer contra o silêncio decretado pela ditadura franquista, essas cartas estão impregnadas de uma potência que extrapola a esfera íntima e obriga a estabelecer relaçóes com uma conjuntura histórica mais ampla, ao mesmo tempo que instigam a reflexáo sobre o papel do poeta e da poesia. Nesse cenário, a voz se constituiu como elemento literário problematizador que pôde indagar o silêncio da História oficial. No que tange aos limites da escritura, essas cartas reafirmam a visáo de um poeta cujo itinerário de vida esteve relacionado com os grandes e trágicos acontecimentos históricos do século XX. Diante deles, Rafael Alberti elegeu crer na inserção social da poesia, ciente, certamente, de que, como crença, essa eleição encontrava suas justificativas racionais sem perder a dimensão do inexplicável.

\section{Referências bibliográficas}

ALBERTI, R. Carta de Rafael Alberti a los presos de España. Guaraguao. El Exilio literario español en América. Madrid: Asociación Centro de Estudios y Cooperación para América Latina, Año 2, No 5, p. 113-115, Autumn, 1997. Disponível em: <http://www.jstor.org/stable/25596025>. Acesso em: 30 jan. 2017.

ALBERTI, R. Poesía III. Edición de Jaime Siles. Barcelona: Seix Barral, 2006.

ANA, M. Testimonio. In: SANTONJA, G. El color de la poesía (Rafael Alberti en su siglo). Tomo II. Madrid: Sociedad Estatal de Conmemoraciones Culturales, 2004, p. 13-20.

ANÔNIMO. A Rafael Alberti (Como mensaje de ańo nuevo desde una cárcel de España). Litoral: revista de la poesía y el pensamiento. Poesía en la cárcel. Historia del enfrentamiento de los poetas contra los abusos del poder. Torremolinos, $2^{\text {a }}$ ed., números 61-62-63, 1976. Disponível em: <http://prensahistorica.mcu.es/ es/consulta/registro.cmd?formato=ficha_comprende\&id=11000194841 $>$. Acesso em 30 jan. 2017. 
AZNAR SOLER, M. Marcos Ana, un poeta en el Penal de Burgos. In: SOBREQUÉS I CALLICÓ, J.; MOLINERO, C. (org.). Los campos de concentración y el mundo penitenciario en España durante la Guerra Civil y el franquismo. Barcelona: Crítica, 2003, p. 445-484.

AYALA, F. Para quién escribimos nosotros. In: La estructura narrativa y otras experiencias literarias. Barcelona: Crítica, 1984, p. 180-204.

BOLETÍN de información - Unión de intelectuales españoles. Año I. 15 de agosto de 1956, México D.F., México.

CABALLÉ, A. El arte epistolar. Mercurio, Número 174, Octubre 2015, p. 6-7.

CAUDET, F. Dialogizar el exilio. In: AZNAR SOLER, Manuel (ed.). El exilio literario español de 1939: actas del Primer Congreso Internacional. Volumen 1. Alicante: Biblioteca Virtual Miguel de Cervantes, 2002, p. 30-55.

CAUDET, F. Cultura y exilio: La revista España Peregrina. Tiempo de historia, año III, n. 35, p. 58-73, 1 oct. 1977. Disponível em: <http://gredos.usal.es/jspui/ bitstream/10366/23742/3/THIII N35 P58-73.pdf>. Acesso em: 26 jan. 2017.

DÍAZ-REGAÑON LABAJO, M.A. José Venegas y España Republicana, un ejemplo de antifascismo en el exilio republicano de argentina. In: AZNAR SOLER, M. (ed.). Escritores, editoriales y revistas del exilio republicano de 1939. Sevilla: Renacimiento, 2006, p. 907-913.

FUNES, F.; SANZ, A. El exilio intelectual republicano español en Argentina: la escritura como espacio imaginario de restauración y discurso en contra del olvido en Rafael Alberti y María Teresa León. 1a ed. Ciudad Autónoma de Buenos Aires: Universidad de Buenos Aires. Carrera Ciencias de la Comunicación, 2016. Disponível em: <http://comunicacion.sociales.uba.ar/wp-content/uploads/sites/16/2013/02/ Funes-Sanz-ok.pdf>. Acesso em 17 fev. 2017.

HANSEN, H.L. Rafael Alberti, el último poeta del 27. In: ALBERTI, R. Caly canto. Madrid: Biblioteca Nueva, 2002, p. 9-83.

LEJEUNE, P. Pour l'autobiographie: chroniques. Paris: Seuil, 1998.

LLORENS, V. Estudios y ensayos sobre el exilio republicano de 1939. Sevilla: Renacimiento, 2006.

MIRANDA, J. Imágenes de la vanguardia poética latinoamericana en la Guerra Civil Española. Caracol, São Paulo, n. 11, p. 244-267, julho 2016. Disponível em: <http://www.revistas.usp.br/caracol/article/view/114987>. Acesso em: 20 fev. 2017.

MORAES, Marco Antonio de. Epistolografia e crítica genética. Ciência e cultura, São Paulo, v. 59, n. 1, p. 30-32, mar. 2007. Disponível em: <http://cienciaecultura. bvs.br/pdf/cic/v59n1/a15v59n1.pdf>. Acesso em: 14 fev. 2017. 
MORAES, Marco Antonio de. Edição da Correspondência reunida de Mário de Andrade: histórico e alguns pressupostos. Patrimônio e memória, Assis, UNESP, v. 4, n. 2, p. 115-128, jun. 2009. Disponível em: <http://pem.assis.unesp.br/ index.php/pem/article/viewFile/114/506>. Acesso em: 14 fev. 2017.

NEIRA, J. Litoral. La revista del 27. In: Litoral. Introducción e indices. Edición facsímil de la colección original de la revista Litoral. Madrid: Sociedad Estatal de Conmemoraciones Culturales, 2007.

SALAÜN, S. El exilio literario en Francia. El Boletín de la Unión de Intelectuales Españoles. In: AZNAR SOLER, Manuel (ed.). El exilio literario español de 1939: actas del Primer Congreso Internacional . Volume 1. Alicante: Biblioteca Virtual Miguel de Cervantes, 2002, p. 189-209.

SALINAS, P. Defensa de la carta misiva y de la correspondencia epistolar. In: Obras completas II. Ensayos completos. Madrid: Cátedra, 2007, p. 849-916.

Mayra Moreyra Carvalho. Doutoranda do Programa de Pós-Graduação em Língua Espanhola e Literaturas Espanhola e Hispano-Americana da Faculdade de Filosofia, Letras e Ciências Humanas da Universidade de São Paulo. Bolsista Capes. Mestre em Literatura pela Universidade de Brasília. Atuou, durante o primeiro semestre de 2017, como professora substituta na Universidade de Brasília, na área de Literatura Espanhola e Hispano-Americana. E-mail: mayramoreyra@gmail.com 